II (Thoratec, Pleasanton, Calif) axial flow pumps have sustained patients for 4 years. Given the reservations about survival advantage and economic viability of cardiac transplantation in United Network for Organ Sharing status II patients, properly structured clinical trials to compare LVADs with transplantation or continued medical therapy are indicated and probably overdue. ${ }^{5}$ Indeed, for those who wish to avoid the side effects of immunosuppression, a rotary blood pump might provide a realistic alternative to a donor heart.

In the meantime, rotary blood pumps can offer symptomatic relief for many patients with heart failure who will never reach a transplant waiting list.

\section{References}

1. McAlister FA, Ezekowitz J, Hooton N, et al. Cardiac resynchronisation therapy for patients with left ventricular systolic dysfunction. A systematic review. JAMA. 2007;297:2502-14

2. Rose E, Gelijns A, Moskowitz A, et al. Long term mechanical left ventricular assistance for end stage heart failure. N Engl J Med. 2001;345:1435-43.

3. Westaby S, Banning AP, Jarvik RK, et al. First permanent implant of the Jarvik 2000 heart. Lancet. 2000;356:900-3.

4. Westaby S, Jarvik RK, Freeland A, et al. Post auricular power delivery for permanent mechanical circulatory support. J Thorac Cardiovasc Surg. 2002; 123:977-83.

5. Cadeiras M, Von Beyern MP, Deng M. Cardiac transplantation. Any role left? Heart Fail Clin. 2007;3:321-48.

\title{
Successful lung transplantation in an octogenarian
}

\author{
Norihisa Shigemura, MD, Stacey Brann, MD, Susan Wasson, CRNP, Jay Bhama, MD, \\ Christian Bermudez, MD, Brack G. Hattler, MD, Bruce Johnson, MD, Maria Crespo, MD, \\ Joseph Pilewski, MD, and Yoshiya Toyoda, MD, Pittsburgh, Pa
}

Advanced recipient age continues to be used as an exclusion criterion for lung transplantation. ${ }^{1}$ However, given the changing age demographics in most developed countries, redefinition of the appropriate recipient age limit for lung transplantation is needed because it has become an established therapeutic option with acceptable mortality for endstage lung diseases. Given those conditions, we recently have expanded our criteria for both recipients and donors in lung transplantation. ${ }^{2}$ We present the case of an 81-year-old man with idiopathic pulmonary fibrosis (IPF) who is the oldest known successful lung transplant recipient reported.

\section{CLINICAL SUMMARY}

An 81-year-old man who had been an active businessman and enjoyed golf after retirement was given a diagnosis of IPF in 2005 and treated with oral steroids and azathioprine. $\mathrm{He}$ became oxygen dependent and severely limited in activities of daily living (from Fletcher Hugh-Jones criteria 4 to 5). After failing all other therapeutic initiatives, he was referred to one major medical center in the United States for lung transplantation evaluation. However, because of his advanced

\footnotetext{
From Cardiopulmonary Transplantation, University of Pittsburgh Medical Center, Pittsburgh, $\mathrm{Pa}$.

Disclosures: None.

Received for publication Jan 21, 2008; revisions received May 26, 2008; accepted for publication June 22, 2008; available ahead of print March 12, 2009.

Address for reprints: Norihisa Shigemura, MD, Department of Thoracic Surgery, Osaka University Graduate School of Medicine, L5, 2-2 Yamada-oka, Suita, Osaka, 565-0871 Japan (E-mail: shigemura@thoracic.med.osaka-u.ac.jp).

J Thorac Cardiovasc Surg 2010;139:e47-8

$0022-5223 / \$ 36.00$

Copyright (c) 2010 by The American Association for Thoracic Surgery doi:10.1016/j.jtcvs.2008.06.044
}

age, he was declined and referred to our center to re-evaluate his lung transplantation candidacy. Although the patient had a past history of prostate cancer in 1992, there was no evidence of recurrence during the 5 years before our re-evaluation, and he was deemed a suitable candidate based on our multidisciplinary transplant selection committee criteria. At the time of listing, he had severely restrictive pulmonary function, with a forced vital capacity of $1.59 \mathrm{~L}(41 \%$ of predicted value), a forced expiratory volume in 1 second of 1.35 $\mathrm{L}$ ( $56 \%$ of predicted value), and a diffusion capacity for carbon monoxide of $3.88 \mathrm{~L} / \mathrm{min} / \mathrm{kpa}$ ( $23 \%$ of predicted value). Furthermore, blood gas on room air showed a $\mathrm{Po}_{2}$ of $48 \mathrm{~mm}$ $\mathrm{Hg}$ and a $\mathrm{PCO}_{2}$ of $36 \mathrm{~mm} \mathrm{Hg}$. The 6-minute walk results were 770 feet on $6 \mathrm{~L}$ of oxygen through a nasal cannula with desaturation to $85 \%$. Cardiac catheterization showed a systolic pulmonary artery pressure of $43 \mathrm{~mm} \mathrm{Hg}$, a transpulmonary gradient of $15 \mathrm{~mm} \mathrm{Hg}$, and mild coronary artery disease. A chest radiograph on admission is shown in Figure 1, $A$.

In April 2007, a 51-year-old man with no smoking history became available as a donor. The donor was 66 inches in height, whereas the recipient was 68 inches. We performed a left single-lung transplantation without cardiopulmonary bypass, during which the allograft ischemic time was 245 minutes. Immunosuppressive therapy consisted of intravenous alemtuzumab (Campath-1H; Genzyme Corporation, Cambridge, Mass) as induction therapy, with oral tacrolimus, mycophenolate mofetil, and prednisone administered postoperatively. Recovery from the procedure was uneventful. $\mathrm{He}$ was extubated on postoperative day 1 and was discharged from the hospital 21 days after transplantation without supplemental oxygen. At present, 1 year after transplantation, the 
A

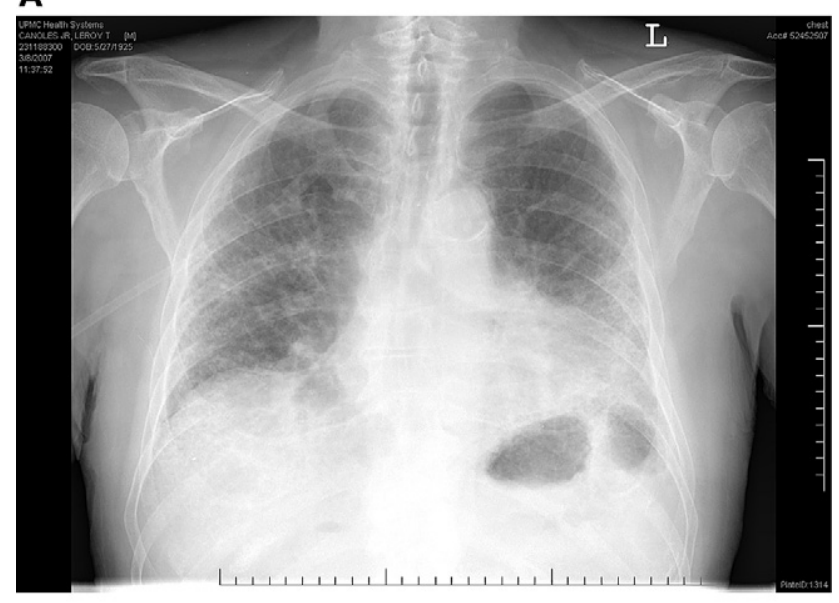

B

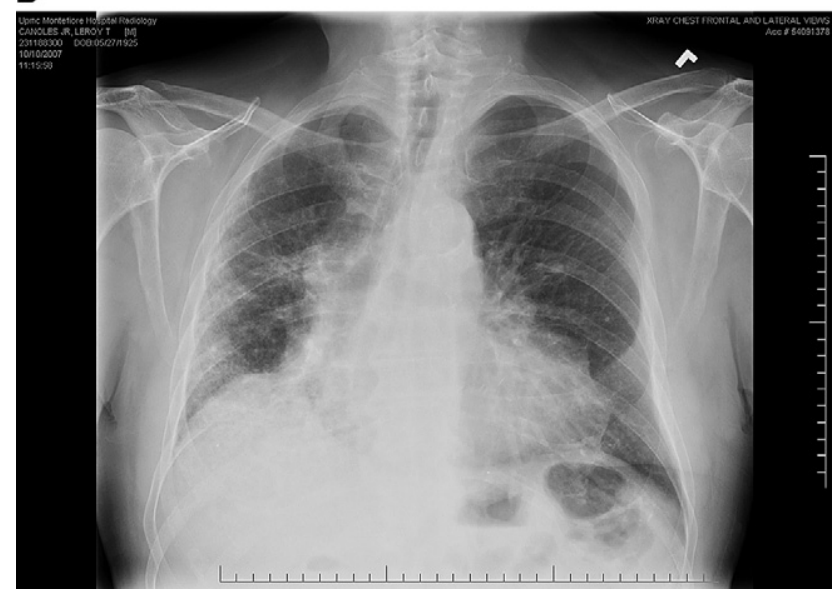

FIGURE 1. Chest roentgenogram on admission (A) and 6 months after left single-lung transplantation (B).

patient leads an independent and active lifestyle and performs normal activities of daily living without dyspnea or the need for oxygen. Recent pulmonary function tests showed a forced vital capacity of $2.43 \mathrm{~L}$ ( $64 \%$ of predicted value) and a forced expiratory volume in 1 second of $2.05 \mathrm{~L}$ ( $86 \%$ of predicted value). A chest radiograph 6 months after left single lung transplantation is shown in Figure 1, $B$.

\section{DISCUSSION}

We report a case of successful single-lung transplantation in an 81-year-old man with respiratory failure caused by IPF. Our reports demonstrated that an acceptable outcome is possible after single-lung transplantation for an octogenarian, despite advanced age. Over the past 2 decades, lung transplantation has become an established life-saving therapy for patients with end-stage lung diseases, and increasing numbers of transplantations are being performed throughout the world. IPF is the second most common indication for lung transplantation in the United States, and most of those patients are older than 50 years. ${ }^{3}$

To date, lung transplantation remains the only intervention proved to confer a survival benefit over the best medical therapy in selected patients with IPF. ${ }^{4}$ However, if a strict age limit of 60 or 65 years were used for lung transplantation, a quarter of the population in North America and Europe would be categorically denied this therapeutic option because of changing age demographics. Several reports have already demonstrated that lung transplantation can be performed with very acceptable immediate and long-term results in appropriately selected patients who are 60 years of age and older. ${ }^{5}$ In our institution approximately $30 \%$ of the recipients since 2004 were older than 60 years, and their overall outcomes have not been compromised compared with those of patients selected less aggressively before 2004 .

Multiple risk factors predictive of higher mortality after lung transplantation, such as prior sternotomy or thoracotomy, body mass index of greater than 25 , increased bilirubin or creatinine levels, and increased pulmonary artery pressure, should be considered in combination when evaluating older recipients for a potential lung transplantation. ${ }^{3}$ However, we believe that age alone should not exclude patients from consideration of lung transplantation. In this case lung transplantation saved an 81-year-old patient from his life-threatening condition and has successfully provided him with qualityof-life improvements for longer than 1 year.

A number of complicated issues remain debatable, including ethical concerns, regarding this important topic, which we intend to investigate more thoroughly in our next report with a larger number of elderly cases of higher age. We consider that additional studies of the effect of advanced age along with other individual risk factors on outcome after lung transplantation will improve preoperative risk prediction and promote improvement of selection criteria for lung transplant recipients.

\section{References}

1. Levine SM. A survey of clinical practice of lung transplantation in North America. Chest. 2004;125:1224-38.

2. Toyoda Y, McCurry KR. Prior cardiac surgery is not a contraindication for lung donor. Ann Thorac Surg. 2007;84:314-6.

3. Trulock EP, Edwards LB, Taylor DO, Boucek MM, Keck BM, Hertz MI. Registry of the International Society for Heart and Lung Transplantation: twenty-second official adult and heart-lung transplant report-2005. J Heart Lung Transplant. 2005; 24:956-67.

4. Thabut G, Mal H, Castier Y, Groussard O, Brugiere O, Marrash-Chahla R, et al. Survival benefit of lung transplantation for patients with idiopathic pulmonary fibrosis. J Thorac Cardiovasc Surg. 2003;126:469-75.

5. Palmer SM, Davis RD, Simsir SA, Lin SS, Hartwig M, Reidy MF, et al. Successful bilateral lung transplant outcomes in recipients 61 years of age and older. Transplantation. 2006;81:862-5. 